\title{
Telephone first consultations in primary care
}

\author{
(c) $(\mathbb{0} \Theta$ OPEN ACCESS \\ Policy makers should reconsider their unequivocal support for these systems
}

\section{Brian McKinstry professor of primary care eHealth ${ }^{1}$, John Campbell professor of general practice and primary care $^{2}$, Chris Salisbury professor of primary health care ${ }^{3}$}

${ }^{1}$ Usher Institute of Population Health Sciences and Informatics, University of Edinburgh, Edinburgh EH16 4UX, UK; ${ }^{2}$ University of Exeter, Exeter, UK; ${ }^{3}$ University of Bristol, Bristol, UK

General practice in the UK, as in many other countries, is under considerable strain. Despite rising list sizes and an increasingly elderly population with complex needs, the number of full time equivalent general practitioners has fallen. ${ }^{1}$ Patients report recent deterioration in the accessibility of GP services. ${ }^{2}$ UK health policy makers have suggested that alternatives to face to face consultations could improve patient access and alleviate staff workload, and local commissioners have invested heavily to promote the uptake of such alternative approaches based on telephone or electronic consulting.

One such approach is "telephone first," in which a GP speaks to all patients on the telephone to decide whether the problem can be resolved by telephone, if a face to face appointment with a doctor or nurse is necessary, or if another professional such as a pharmacist might be more appropriately consulted. Commercial companies marketing these systems report large reductions in GP workload and impressive reductions in attendance at emergency departments and emergency admissions. $^{34}$

The linked paper by Newbould and colleagues (doi:10.1136/ bmj.j4197) is therefore timely. ${ }^{5}$ Although there have been previous randomised controlled trials and observational studies of telephone triage of requests for same day face to face consultations, ${ }^{6-10}$ this is the first independent evaluation of such telephone first systems for all consultation requests.

The results support the conclusions of earlier studies ${ }^{7-10}$ that much of the work of general practice can be managed on the telephone but that many patients (almost half in this study) need to be seen in person. Although the delay to see or speak to a doctor is greatly reduced by the introduction of telephone first systems, overall workload for doctors increases. The marked reduction in time spent consulting in surgery is more than compensated for by an increase in time spent on telephone consultations. The telephone first approach was not associated with a reduction in attendances at emergency departments, as proponents have claimed, ${ }^{34}$ and led to an increase in emergency admissions. Introduction of such systems might increase overall costs.

There was distinct variation among practices in how well the system functioned. Some noted large reductions in workload while others experienced big increases. The reasons for this were unclear and warrant further exploration. The authors observed that better organised practices seemed to fare better than practices that were overwhelmed before they adopted a telephone first system. Some practices did not fully implement the telephone first approach, but subanalyses of these variations in implementation showed little association with outcomes.

Patients too expressed varied views. While, overall, they liked the quicker access to advice and the convenience of not having to attend the practice, some found the system frustrating-with difficulties getting through or long waits for a call back. In telephone first practices, the proportion of patients preferring the new system was similar to the proportion preferring the old one, and the proportion who would recommend their practice to friends fell.

A substantial minority of patients found telephone communication difficult. This could be an underestimate as people who have problems with telephone consulting (those whose first language is not English, with learning difficulties, or with low literacy skills) are also less likely to return a survey. The authors don't report the cost implications for patients.

The authors acknowledge some of the study's shortcomings. The effect of telephone first on other parts of the health service, such as nursing and pharmacy, were not measured. Commercial companies marketing the systems provided appointments data, and it is unclear how the authors overcame the difficulties in analysing routine appointments data, including the cleaning and recoding often required to make data suitable for analysis. Large amounts of data about the duration of appointments were missing and so had to be imputed. The safety of telephone consulting was not covered, and the reported increase in 
emergency admissions associated with telephone first systems is of potential concern.

These findings largely underline those of earlier UK studies exploring telephone triage. ${ }^{7-11}$ The study by Newbould and colleagues should cause practices to think carefully about the wider, possibly unanticipated, consequences of a switch to a telephone first system and should lead policy makers to reconsider their unequivocal support for such systems.

Telephone consulting could work well for patients with straightforward problems or those needing routine follow-up. Practices might find it helpful as a means of deferring work during times of doctor shortage. However, it is unlikely to lower workload. Indeed, making it easier to access an initial consultation may result in increased workload in the short term and greater problems long term through supply induced demand.

Telephone first systems alone will not solve the perennial problem of ensuring timely, safe, effective, and equitable access to primary care when demand is increasing and resources are not. It is also yet another reminder of the importance of independent evaluation of initiatives before investment in widespread implementation.

We are grateful for the support and input of Barbara Tilbury, patient representative, who read and commented on a draft of this editorial. Competing interests: We have read and understood BMJ policy on declaration of interests and declare we have been involved in UK NIHR funded academic research investigating the potential for telephone triage in primary care service delivery.
Provenance and peer review: Commissioned, not peer reviewed.

1 BMA. BMA warns that fall in GP numbers shows crisis deepening in general practice. BMA, 2017. https://www.bma.org.uk/news/media-centre/press-releases/2017/march/bmawarns-that-fall-in-gp-numbers-shows-crisis-deepening-in-general-practice.

2 NHS England. GP patient survey 2017 - headline figures. https://www.england.nhs.uk/ statistics/2017/07/06/gp-patient-survey-2017/.

3 GP Access. 2017. http://gpaccess.uk/.

4 Productive Primary Care. 2017. http://www.productiveprimarycare.co.uk/.

5 Newbould J, Abel G, Ball S, et al. Evaluation of telephone first approach to demand management in English general practice: observational study. BMJ 2017;358:j4197.

6 Jiwa M, Mathers N, Campbell M. The effect of GP telephone triage on numbers seeking same-day appointments. Br J Gen Pract 2002;358:390-1.pmid:12014537.

7 McKinstry B, Walker J, Campbell C, Heaney D, Wyke S. Telephone consultations to manage requests for same-day appointments: a randomised controlled trial in two practices. Br J Gen Pract 2002;358:306-10.pmid:11942448.

8 Richards DA, Meakins J, Tawfik J, et al. Nurse telephone triage for same day appointments in general practice: multiple interrupted time series trial of effect on workload and costs. BMJ 2002;358:1214-7. doi:10.1136/bmi.325.7374.1214 pmid:12446539.

9 Lattimer V, George S, Thompson F, et al. The South Wiltshire Out of Hours Project (SWOOP) Group. Safety and effectiveness of nurse telephone consultation in out of hours primary care: randomised controlled trial. BMJ 1998;358:1054-9. doi:10.1136/bmj.317. 7165.1054 pmid:9774295.

10 Campbell JL, Fletcher E, Britten N, et al. Telephone triage for management of same-day consultation requests in general practice (the ESTEEM trial): a cluster-randomised controlled trial and cost-consequence analysis. Lancet 2014:358:1859-68. doi:10.1016/ S0140-6736(14)61058-8 pmid:25098487.

11 Holt TA, Fletcher $E$, Warren $F$, et al. Telephone triage systems in UK general practice: analysis of consultation duration during the index day in a pragmatic randomised controlled trial. Br J Gen Pract 2016;358:e214-8. doi:10.3399/bjgp16X684001. pmid:26917660.

Published by the BMJ Publishing Group Limited. For permission to use (where not already granted under a licence) please go to http://group.bmj.com/group/rights-licensing/ permissions

This is an Open Access article distributed in accordance with the Creative Commons Attribution Non Commercial (CC BY-NC 4.0) license, which permits others to distribute, remix, adapt, build upon this work non-commercially, and license their derivative works on different terms, provided the original work is properly cited and the use is non-commercial. See: http://creativecommons.org/licenses/by-nc/4.0/. 